\title{
Staff Nurses' Perception of Head Nurses' Support for their Creativity
}

\section{Gehad Mohamad Amin Awad',Safaa Mohamed EL-Demerdash ${ }^{2}$, Walaa Mostafa Eid ${ }^{3}$}

Nursing Specialist El Santa Central Hospital, ${ }^{2}$ professor, ${ }^{3}$ Lecturer, ${ }^{2,3}$ Nursing Services Administration, Faculty of Nursing, university

\begin{abstract}
Background: Head nurses play a vital role in supporting staff nurses in carrying out their duties. Staff nurses' creativity is a pivotal in promoting health and wellbeing of patients. So, they need strong support from head nurses to facilitate their creativity. Aim: This study aimed to assess the staff nurses' perception of head nurses' support for their creativity. Subjects and Method: Research design: Descriptive research design was used in the study. Setting: The study was conducted at Tanta University Main Hospital. Subjects: Consisted of all staff nurses 710 from the above mentioned setting. Tools: two tools were used to collect the data. Tool I: Head nurses' support scale. Tool II: Staff nurses' creativity scale. Results: Majority of staff nurses had high perception of head nurses' support as a total. Regarding to staff nurses' creativity, majority of staff nurses had high percentage of creativity as a total. Conclusion: There were statistically significant positive correlation between staff nurses' perception of head nurses' support for their creativity. Recommendation: it was recommended that heath care organization managers including head nurses should provide suitable, supportive environment for staff nurses to create new ideas and supporting their creativity. Head nurses have to provide opportunities for staff nurses to express their ideas and opinions, as well as setup an orientation programs for newly staff nurses about the importance of creativity and its role in developing heath care systems.
\end{abstract}

Keywords: Creativity, Head Nurses, Staff Nurses, Support. 


\section{Introduction}

As the complexity of health care and nursing escalates, staff nurses are asked to provide creative solutions in nursing care practices. Dealing with patients of different ages, health conditions and back grounds have made creativity a vital element in nursing duties. Staff nurses feel supported by their head nurses are more likely to succeed in their position and more likely to develop creative ideas to their $\operatorname{departments}^{(1,2)}$.

Head nurses' support is the head nurses' act of helping staff nurses by giving them encouragement or actions and work practices that are designed to facilitate staff nurses' effectiveness and wellbeing $(1,3)$. Head nurses' support for staff nurses' creativity have different components either emotional, informational, instrumental and appraisal. Emotional support reflects the perception that head nurses show empathy, compassion and genuine concern for staff nurses wellbeing and is focused on meeting nurses' needs to feel valued, cared for, respected and liked. Informational support is the provision of advice, guidance, suggestions and information from head nurses to staff nurses that can be used to solve a given problem ${ }^{(4-6)}$.

Instrumental support is the provision of financial and practical assistance, resources and time that is needed to perform key tasks and responsibilities ${ }^{(7,8)}$. Appraisal support includes feedback given to staff nurses to assist them in selfevaluation or in appraising a situation. Head nurses' support for staff nurses who try to act in an creative way by questioning their ideas, stimulate them to think creatively and enable them to generate new ideas this enhances staff nurses' awareness towards creativity ${ }^{(9-11)}$.

Staff nurses' creativity is the capacity or ability of nurses to create, discover or produce new idea including the reshaping or rearrangement of what is already known to them ${ }^{(12)}$. Creativity is a daily occurrence which is fundamental to patient-nurse interactions and a multifaceted issue in nursing profession as well as the most important key to improvement of both nursing and human services. Furthermore, it is perceived as the formation of appropriate, helpful and novel thoughts $^{(13,14)}$.

Nurses' creativity is the activity or mental work involved in obtaining new something. For the nurses to be creative they should be equipped for seeing things in new ways or from an alternate viewpoint, ready to develop new solutions or new options, communicate values and ideas ${ }^{(15)}$. Nurses' creativity involves six elements which are originality, intellectual 
fluency, mental flexibility, sensitivity to problems, ability analysis and risk taking. Originality element is the ability of nurses to develop ideas that are statistically unusual, unique or novel ${ }^{(16,17)}$.

Intellectual fluency element is their ability to think well in order to develop a lot of ideas, responses, solutions or questions. Mental flexibility element is the nurse's ability to easily integrate old ways of thinking adopt new ones and generate ideas, responses, questions or solutions in a plenty of categories. Sensitivity to problems is the staff nurses' ability to find and discover problems before others explore it or notice it again Ability analysis element is staff nurses' ability to schedule details in order to adjust or extend upon an idea or general scheme ${ }^{(18,19)}$.Risk taking element is their ability to defend their ideas by argument and proof, accept others' criticisms and their willing to confront ${ }^{(20)}$.

\section{Significant of the study}

Health-care system contains many threats and problems forces nurses with a critical role in patient care to resort to effective and creative solutions $(20,21)$. This threats including unexpected situations in different conditions in the ever-changing and developing working areas within the health system. Staff nurses need to be creative to deal with these threats and problems. As creativity is the basic engine for the development of health care workers and organization so it is important to provide supportive environment for staff nurses to generate new ideas ${ }^{21,22)}$.

Nurses such as every individual has the potential and need to be creative. So, support either individually and organizationally is important for staff nurses to be creative. While solving the problems faced by nurses in patient care, the organizational and technological infrastructure of the organization affects the process of creativity positively. Head nurses should contribute to this process by motivating team members, creating a trusting environment and acting in line with ethical principles ${ }^{(4,12,22}$.

When staff nurses feel supported from their head nurses to suggest new processes and share their ideas in a supported environment, they will be more likely to think creatively about their work. Head nurses can affect creative behavior and creative performance of staff nurses by influencing the nurses' perceptions of a supportive work conditions ${ }^{(3,6,23)}$.

\section{Aim of the Study}

The aim of the study is to assess staff nurses' perception of head nurses' support for their creativity.

\section{Research question}


What is the relation between staff nurses' perception of head nurses' support for their creativity?

\section{Subjects and Method}

Study design : Descriptive research design was used in present study to describe levels of head nurses' support , staff nurses' levels of creativity and to examine relation between those variables $^{(24)}$.

Setting: The present study was conducted at Tanta University Main Hospital affiliated to ministry of higher education with capacity (2035) beds. It includes General Medicine Department , Tropical, Cardio, Obstetric, Chest , Pediatric , Oncology and Psychiatric departments.

Subject: All staff nurses $(n=710)$ from the above mentioned setting. included the following departments ; general medical $(n=100)$, tropical $(\mathrm{n}=50)$, cardio $(\mathrm{n}=110)$, obstetric $(\mathrm{n}=114)$, chest $(n=58)$, pediatric $(n=34)$, oncology $(n=$ $180)$ and psychiatric $(\mathrm{n}=144$ (.

\section{Tools of data collection}

To achieve the aim of the study the following tools were used.

Tool I: Head nurses' support questionnaire. It included two parts;

Part one: staff nurses ' characteristics such as: age, marital status, gender, qualification, years of experiences and department.

\section{Part two:Head nurses' support} questionnaire. This part was developed by the researcher guided by El-Shaer (2002) (25) , Papadatou et.al (1999) ${ }^{(26)}$ and recent related literatures ${ }^{(27-30)}$ to assess levels of head nurses' support among staff nurses .It consisted of 31 items classified into four components ; It consisted of 31 items classified into four components : emotional support included(10 items), informational support included (5items),instrumental support included (5items) , appraisal support included(11items) .

\section{Scoring System}

Staff nurses' responses were measured on five Points - Likert Scale ranging from strongly agree (5), agree(4), Little agree (3), disagree(2) and strongly disagree(1), which concluded to three points where: Agree $=$ strongly agree + agree , Disagree $=$ strongly disagree + disagree. The total score was statistically calculated by summing scores of all categories where: high level of support $\geq 75 \%$,moderate level of support $60-75 \%$,low level of support $60 \%$.

\section{Tool 2:Staff Nurses' Creativity}

Questionnaire .This tool was developed by the researcher guided by Tabarestania et 
al (2014) $\left({ }^{31)}\right.$, kalf (2010) ${ }^{(32)}$ and recent related literatures $(33-36)$ to assess staff nurses' level of creativity. It contained 26 items classified into six elements: originality included (3 items ), intellectual fluency included (6 items), mental flexibility included (4 items), sensitivity to problem included (4 items), ability analysis included (4 items ), Risk taking included (5 items) .

\section{Scoring System}

Staff nurses' responses were measured on five Points - Likert Scale ranging from (5) always to (1) never. Always +often = often, rarely + never $=$ never, the total score was statistically calculated by summing scores of all categories where: high level of creativity $\geq 75 \%$, moderate level of creativity $60-75 \%$, low level of creativity $60 \%$.

\section{Method}

1-Official permission was obtained from Tanta university Main hospital responsible authorities to conduct the study.

2-Ethical consideration: Approval of Ethical committee at faculty of nursing was obtained. The researcher introduced herself to the participants and written informed consent of staff nurses were obtained to participate in the study after a full explanation of the purpose of the study was done. Staff nurses were informed about privacy of information, confidentiality of data and their right to withdrawal.

3- The study tools were developed and designed by the researcher based on recent literatures.

4-Tools (I, II) were translated into Arabic language and reviewed with the supervisors and submitted to a jury of five experts in the area of specialty to check content validity of its items. The experts were ; two professor of Nursing services Administration ,two assistant professor of Nursing Services Administration, , one assistant professor of Psychiatric and Mental Health Nursing from Faculty of Nursing, Tanta University.

5-The experts' responses were presented in four points rating scale ranging from (4-1) : 4 = strongly relevant , $3=$ relevant , $2=$ little relevant , $1=$ not relevant . Necessary modifications were done including; clarification, omission of certain items and adding others and simplifying work related words.

- The face validity value of tool (1) part 2 :Head nurses' support questionnaire $=90.0 \%$; Tool (2): Staff nurses' creativity questionnaire was $90.0 \%$

6-Reliability of tools was tested using Cronbach Alpha Coefficient test . Reliability of tool (1) part 2: Head 
nurses' support questionnaire $=0.387$;

Tool (2): Staff nurses' creativity questionnaire was 0.211 .

7-A pilot study was carried on a sample of $10 \%$ of the subject $(n=80)$ and excluded from the main study sample during the actual collection of the data. The pilot study was done to test the tool for clarity and applicability, relevance of the questions and to determine needed time to complete the questionnaire. The pilot study was done out after the experts' opinion and before staring the actual collection of data .According to feedback from pilot study, the tool was modified by the researcher. The estimated time to complete the questionnaire items from staff nurses was 15-20 minutes.

8- Head nurses' support questionnaire and Staff nurses' creativity questionnaire were used to collect data from identified subject.

9 -Data collection phase : the data were collected from the identified nurses .The researcher met the respondents' staff nurses at their setting and distributed the questionnaire and asked them to fill it and returned it back.

10- The staff nurses recorded their answers in the presence of the researcher to ascertain that all questions were answered .The data was collected over a period of six months started from November 2019 until April 2020.

\section{Statistical analysis of data}

Data were fed to the computer and analyzed using BM SPSS software package version 20.0 (Armonk, NY: BM CORP) qualitative data were described using number and percent. Quantitative data were described using mean, standard deviation. Significance of the obtained results was judged at the $5 \%$ level.

\section{The used tests were:}

1-Student t. test: for normally distributed qualitative variables, to compare between two studied groups.

2- F. test (ANOVA): for normally distributed quantitative variables, to compare between more than two studied groups.

3-Pearson Coefficient: to correlate between two normally distributed quantitative variables.

\section{Results}

Table (1): Shows percentage distribution of staff nurses' characteristics. It showed that $(77.5 \%)$ of staff nurses aged 2534years old compared with $0.8 \%$ are aged $\geq 45$ years with mean age $29.96 \pm 4.38$. It illustrated that the majority of staff nurses $(95.1 \%)$ are married .Also the majority of staff nurses $(96.3 \%)$ are females and the majority of them had Associate degree 
qualification which represent $(55.5 \%)$. Regarding their years of experience, more than half $(81.0 \%)$ of staff nurses had 5-15 year of experience with the mean $9.30 \pm$ 4.49. (22.5\%) staff nurses' working in Oncology department but only $(4.1 \%)$ in Pediatric department.

Table (2): Shows correlation between staff nurses' perception of head nurses' support for their creativity, from the table it was observed that staff nurses' total creativity, originality, mental flexibility, ability analysis and risk taking elements of creativity had statistically significant positive correlation with their perception of head nurses' total, emotional, informational and instrumental support at $\mathrm{p}$ $\leq 0.05$.

Staff nurses' ability analysis and risk taking elements of creativity was significantly correlated with their perception of head nurses' emotional and instrumental support at $\mathrm{p} \leq 0.05$.

Staff nurses' mental flexibility elements of creativity had statistically significant correlation with their perception of head nurses' instrumental and appraisal support at $\mathrm{p} \leq 0.05$.

Staff nurses' originality elements of creativity had statistically significant correlation with their perception of head nurses' emotional and total support at $\mathrm{p} \leq$ 0.05 .
Staff nurses' intellectual fluency, and sensitivity to problems elements of creativity showed statistically significant correlation with their perception of head nurses' informational support at $\mathrm{p} \leq 0.05$.

Figure (1): Shows overall of staff nurses' perception of head nurses' support. It was observed that 'the majority $(\% 87.7)$ of staff nurses had high perception of head nurses' support as a total.

Figure (2): Illustrates levels of staff nurses' perception of head nurses' support. High percentage of staff nurses ranged from $76.2 \%$ to $67.9 \%$ had high perception of emotional support, appraisal support instrumental support, and Informational components of head nurses' support.

Figure (3) Displays mean percentage of staff nurses' perception of head nurses. From the table, it was observed that the highest mean percentage of staff nurses was given to emotional support (81.08 \pm $6.83)$,followed by informational support $(80.80 \pm 9.38) \quad$, appraisal support( 80.69 $\pm 6.56)$, and instrumental support 79.78 \pm 9.99 . with total mean percentage $80.69 \pm$ 4.38 .

Figure (4): Reveals overall levels of staff nurses' creativity. It was observed that, the majority $(72.7 \%)$ of staff nurses had high percentage of creativity as a total.

Figure (5): Reveals levels of staff nurses' creativity. High percentage of staff nurses 
ranged from $67.6 \%$ to $51.0 \%$ had high levels of ability analysis, risk taking, originality, sensitivity to problems, mental flexibility and intellectual fluency elements of staff nurses' creativity.

Figure (6): Shows mean percentage of staff nurses' creativity elements. It was observed that the highest mean percentage of staff nurses was given to the ability analysis $(81.18 \pm 11.27)$,followed by originality $(80.07 \pm 14.13)$, risk taking $(80.04 \pm 9.87)$, sensitivity to problems $78.25 \pm 13.58$, intellectual fluency 77.05 \pm 11.73 , and mental flexibility76.93 \pm 13.66 with total mean percentage $78.77 \pm$ 5.53 
Table (1): Percentage distribution of staff nurses' characteristics

\begin{tabular}{|c|c|c|}
\hline \multicolumn{2}{|c|}{ Staff nurses $(\mathrm{N}=710)$} & \multirow{2}{*}{ Characteristics } \\
\hline \multirow[t]{2}{*}{$\%$} & No. & \\
\hline & & Age (years) \\
\hline 11.0 & 78 & $<25$ \\
\hline 77.5 & 550 & $25-34$ \\
\hline 10.7 & 76 & $35-44$ \\
\hline 0.8 & 6 & $? 45$ \\
\hline \multicolumn{2}{|c|}{$21.0-50.0$} & Min. - Max. \\
\hline \multicolumn{2}{|c|}{$29.96 \pm 4.38$} & Mean \pm SD. \\
\hline & & Marital status \\
\hline 4.1 & 29 & Single \\
\hline 95.1 & 675 & Married \\
\hline 0.8 & 6 & $\begin{array}{l}\text { Others } \\
\text { Gender }\end{array}$ \\
\hline 3.7 & 26 & Male \\
\hline \multirow[t]{2}{*}{96.3} & 684 & Female \\
\hline & & Qualification \\
\hline 10.0 & 71 & Diploma degree \\
\hline 55.5 & 394 & Associate degree \\
\hline \multirow[t]{2}{*}{34.5} & 245 & Bachelor degree \\
\hline & & Years of experience \\
\hline 13.5 & 96 & $<5$ \\
\hline 81.0 & 575 & $5-15$ \\
\hline 4.4 & 31 & $16-20$ \\
\hline 1.1 & 8 & $>20$ \\
\hline \multicolumn{2}{|c|}{$0.50-30.0$} & Min. - Max. \\
\hline \multicolumn{2}{|c|}{$9.30 \pm 4.49$} & Mean \pm SD. \\
\hline & & Department \\
\hline 12.7 & 90 & General medicine \\
\hline 6.3 & 45 & Tropical \\
\hline 4.1 & 29 & Pediatric \\
\hline 7.3 & 52 & Chest \\
\hline 14.1 & 100 & Cardio \\
\hline 14.6 & 104 & Obstetric \\
\hline 18.3 & 130 & Psychiatric \\
\hline 22.5 & 160 & Oncology \\
\hline
\end{tabular}


Table (2): Shows correlation between staff nurses' perception of head nurses' support for their creativity

\begin{tabular}{|c|c|c|c|c|c|c|}
\hline \multicolumn{5}{|c|}{ Nurses' perception } & & \multirow[b]{2}{*}{ Nurses' creativity } \\
\hline Total & $\begin{array}{l}\text { Appraisal } \\
\text { support }\end{array}$ & $\begin{array}{l}\text { Instrumental } \\
\text { support }\end{array}$ & $\begin{array}{l}\text { Informationa } \\
\text { I support }\end{array}$ & $\begin{array}{l}\text { Emotional } \\
\text { support }\end{array}$ & & \\
\hline $0.138^{*}$ & 0.051 & 0.068 & -0.057 & $0.209^{*}$ & $R$ & \multirow{2}{*}{ Originality } \\
\hline$k 0.001^{*}$ & 0.173 & 0.069 & 0.129 & $<0.001^{*}$ & $\mathbf{P}$ & \\
\hline 0.056 & -0.016 & 0.047 & -0.069 & 0.142 & $\mathbf{R}$ & \multirow{2}{*}{ Intellectual fluency } \\
\hline 0.133 & 0.673 & 0.212 & 0.066 & $<0.001^{*}$ & $\mathbf{P}$ & \\
\hline $0.149^{*}$ & $0.109^{*}$ & $0.165^{*}$ & 0.003 & 0.059 & $\mathbf{R}$ & \multirow{4}{*}{$\begin{array}{l}\text { Mental flexibility } \\
\text { Sensitivity to problems }\end{array}$} \\
\hline$<0.001^{*}$ & $0.004^{*}$ & $<0.001^{*}$ & 0.941 & 0.115 & $\mathbf{P}$ & \\
\hline 0.007 & 0.022 & 0.044 & $-0.079^{*}$ & 0.014 & $\mathbf{R}$ & \\
\hline 0.845 & 0.556 & 0.243 & $0.035^{*}$ & 0.719 & $\mathbf{P}$ & \\
\hline $0.101^{*}$ & -0.033 & $0.182^{*}$ & -0.004 & $0.105^{*}$ & $\mathbf{R}$ & \multirow{2}{*}{ Ability analysis } \\
\hline $0.007^{*}$ & 0.383 & $<0.001^{*}$ & 0.914 & $0.005^{*}$ & $P$ & \\
\hline $0.104^{*}$ & 0.017 & $0.132^{*}$ & -0.002 & $0.094^{*}$ & $\mathbf{R}$ & \multirow{4}{*}{ Risk taking } \\
\hline $0.006^{*}$ & 0.657 & $0.000^{*}$ & 0.953 & $0.012^{*}$ & $P$ & \\
\hline $0.195^{*}$ & 0.052 & $0.224^{*}$ & $-0.081^{*}$ & $0.224^{*}$ & $\mathbf{R}$ & \\
\hline $0.000^{*}$ & 0.164 & $<0.001^{*}$ & $0.030^{*}$ & $<0.001^{*}$ & $\mathbf{P}$ & \\
\hline
\end{tabular}




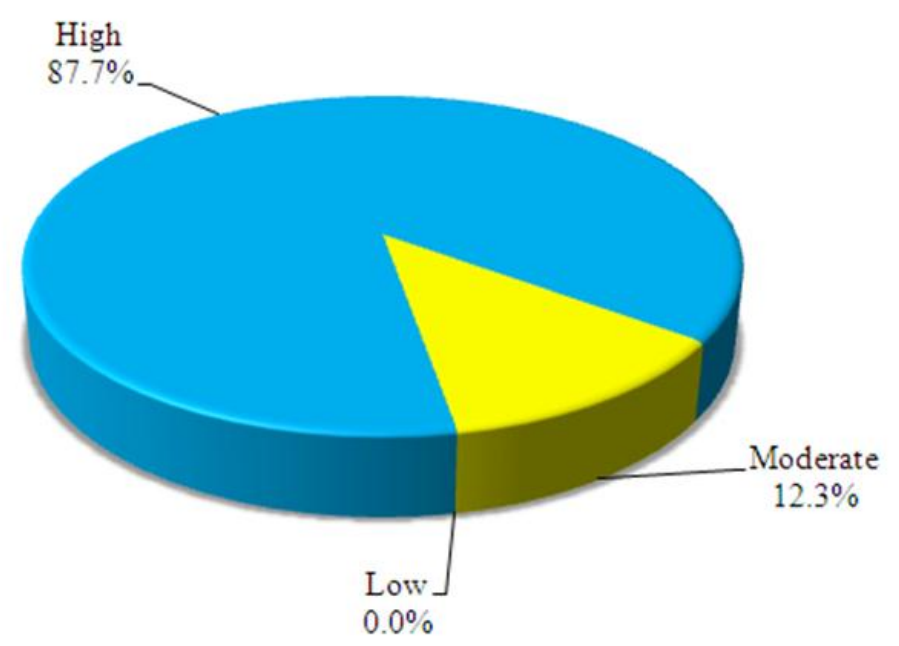

Figure (1): Overall of staff nurses' perception of head nurses' support. $(n=710)$

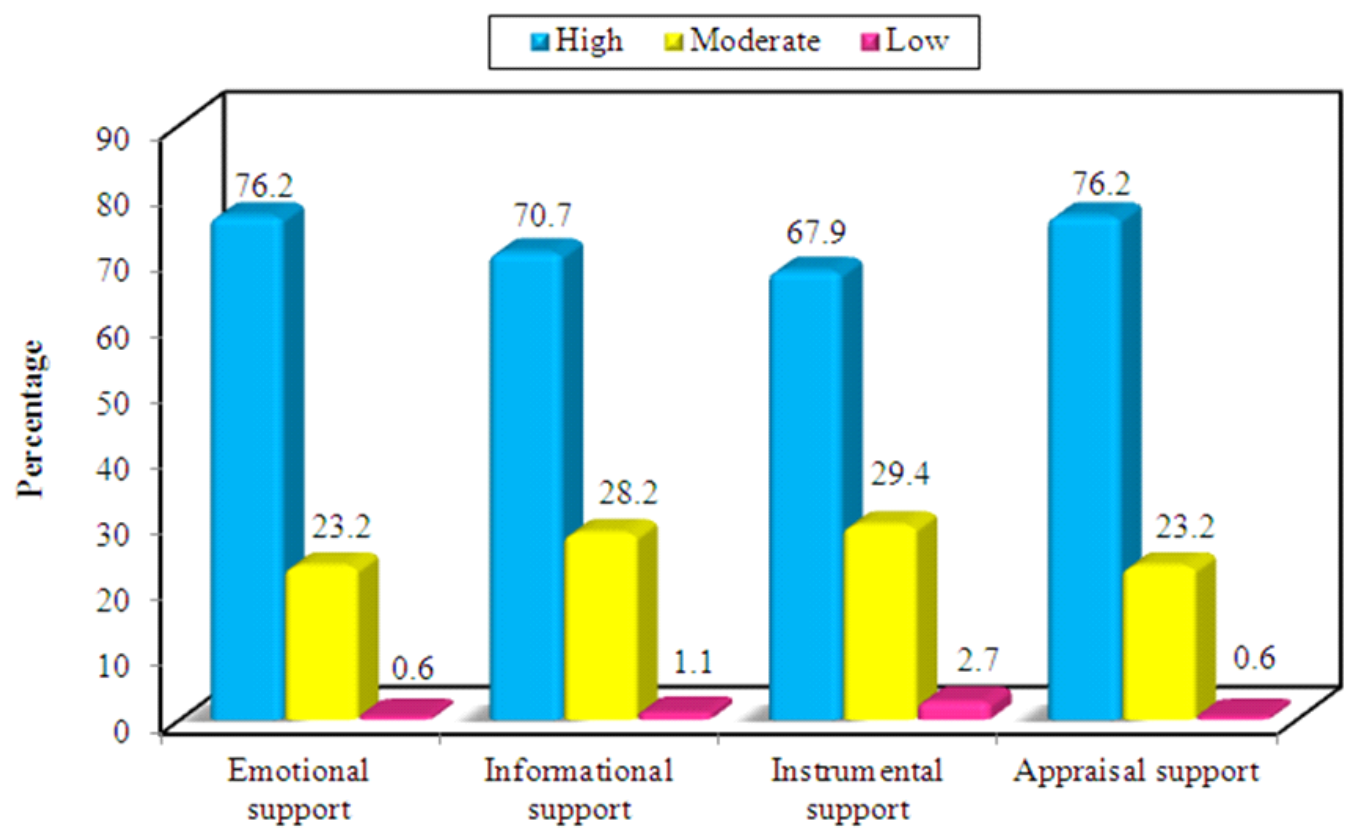

Figure (2): Levels of staff nurses' perception of head nurses' support. $(n=710)$ 


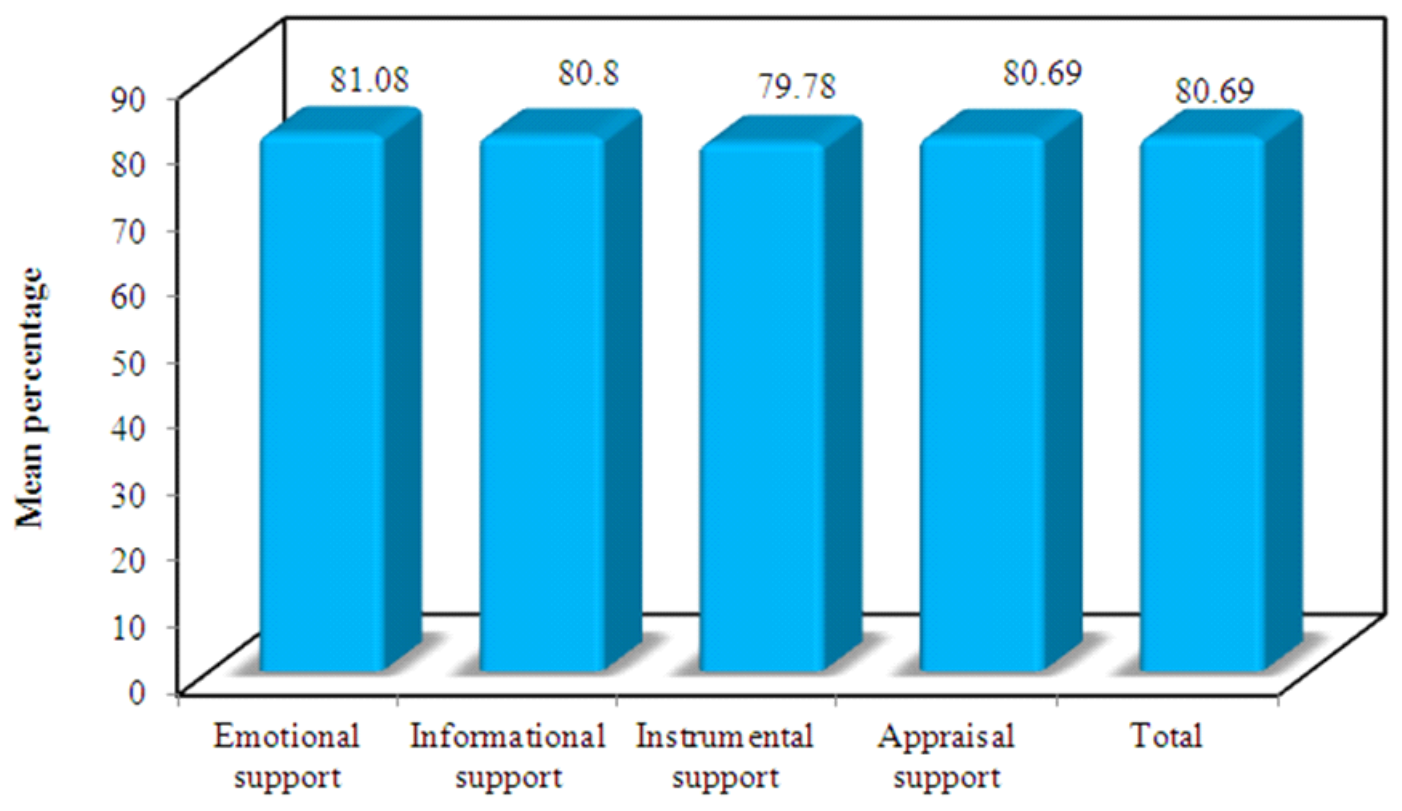

Figure (3):Mean percentage and score of staff nurses' perception of head nurses' support.

$(n=710)$

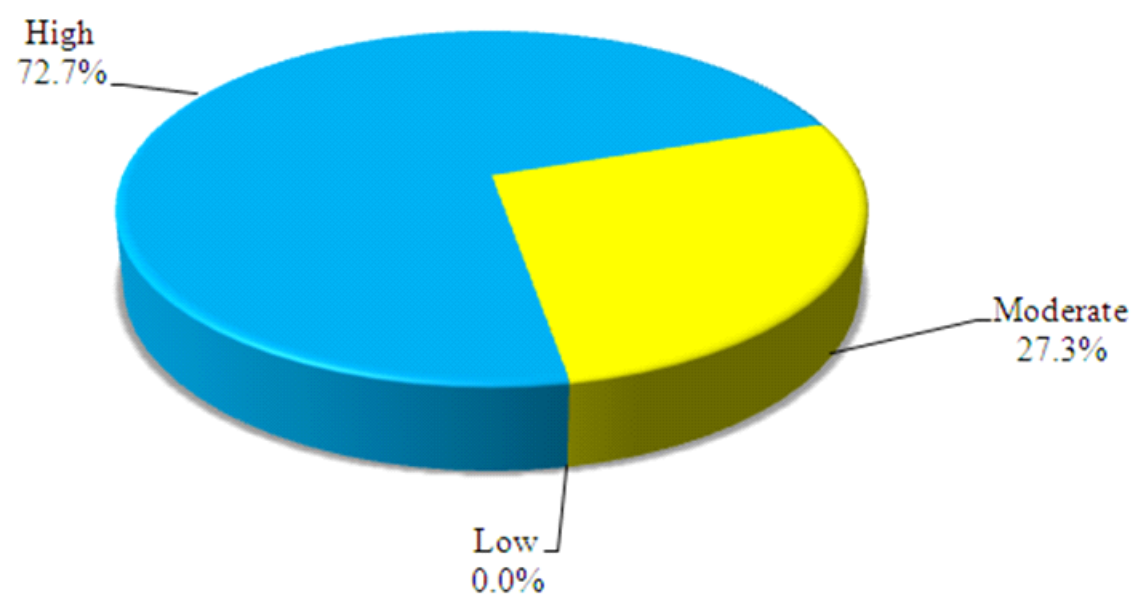

Figure (4): Overall levels of staff nurses' creativity $(n=710)$ 


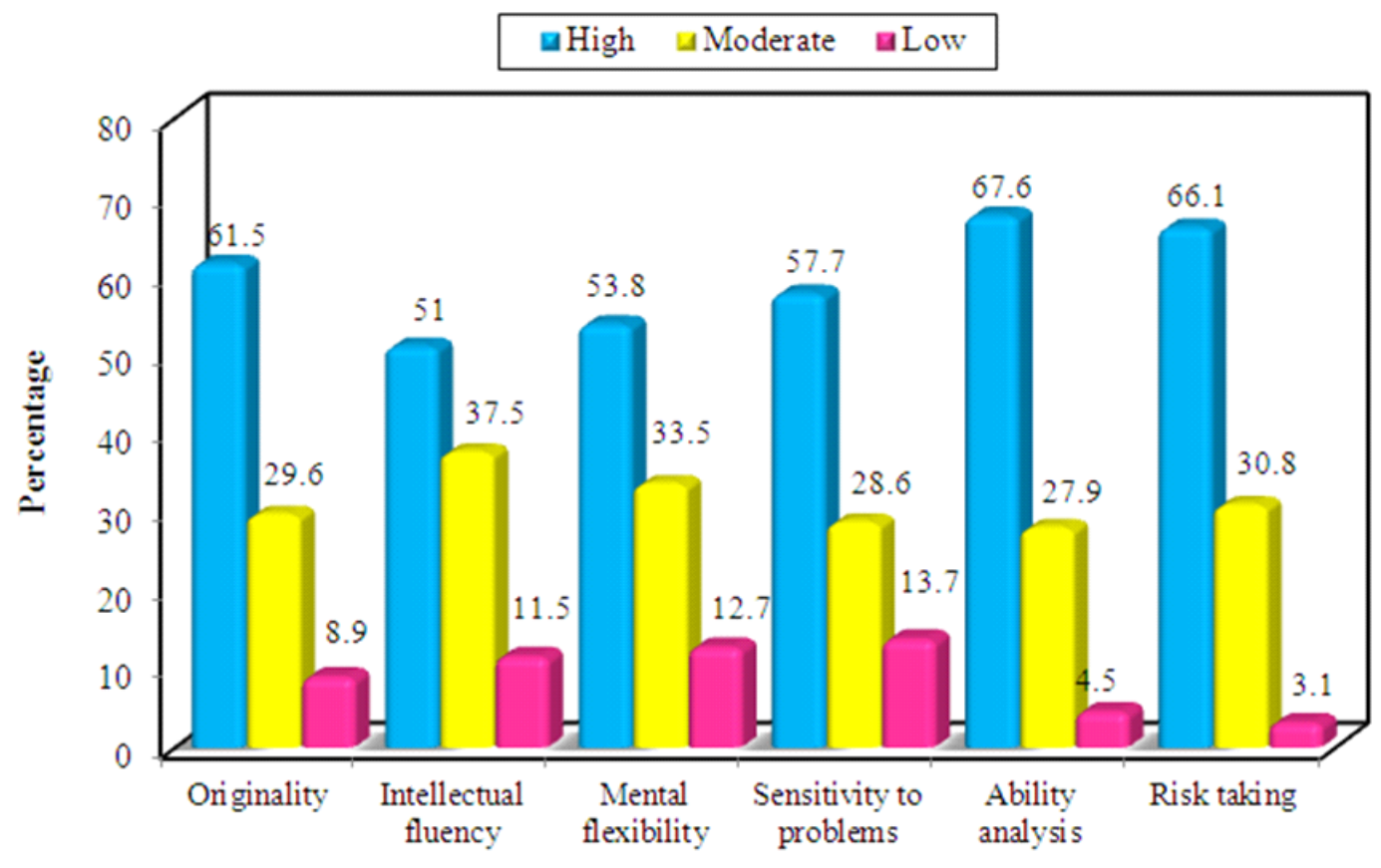

Figure (5): $\quad$ levels of staff nurses' creativity $(n=710)$

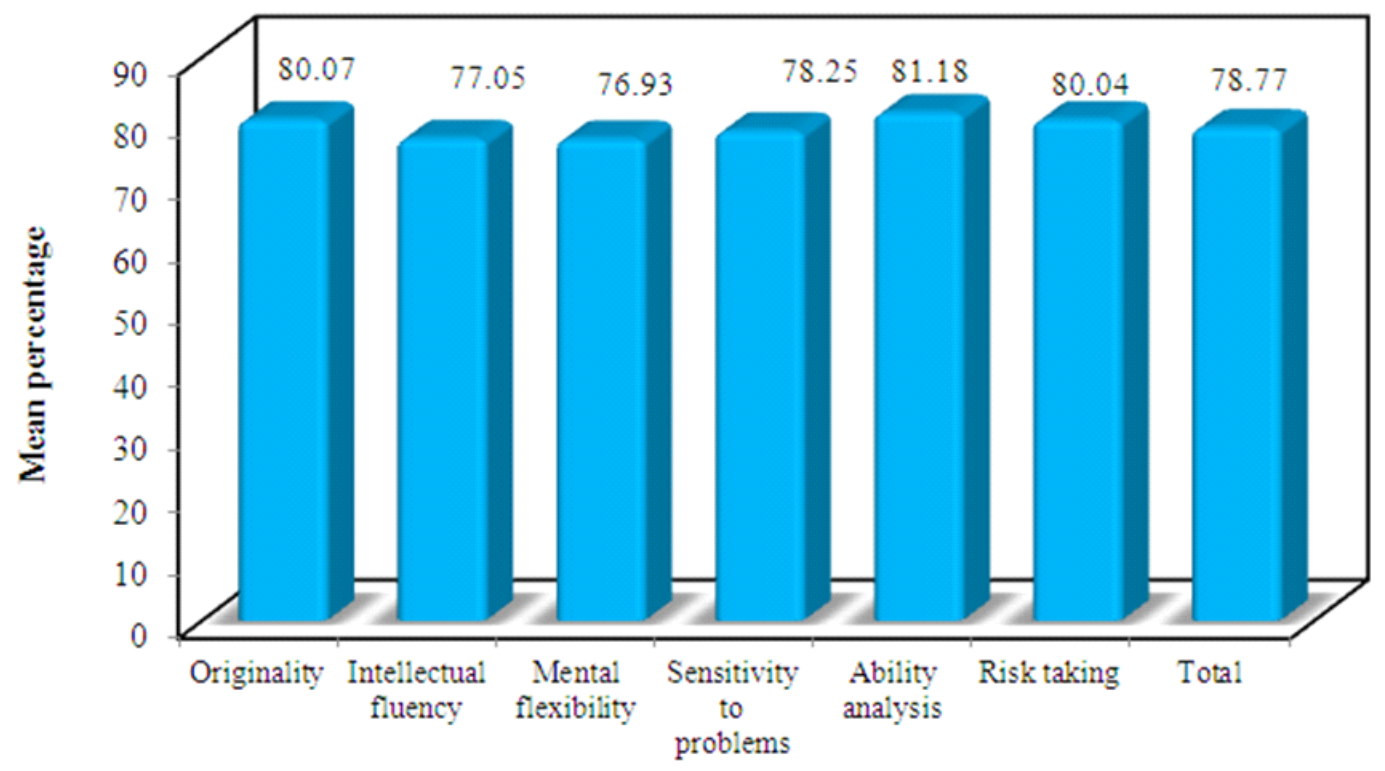

Figure (6): Mean percentage of staff nurses' creativity $(n=710)$ 


\section{Discussion}

Head nurses' support to staff nurses is amongst of work demands, which may possibly improve their creativity ${ }^{(37)}$. Staff nurses often encounter with unexpected situations and they take care of patients with different backgrounds and health conditions, hence they need to go beyond nursing routines and acquire creative thinking to make useful decisions ${ }^{(38)}$.

American Association of Critical-Care Nurses, and the American Organization of Nurse Executives identify head nurses' support as essential to a healthy work environment. When head nurses supports staff nurses by answering to their questions, giving them suggestions, information, and constructive feedback, as well as listening to them, they are more likely to generate creative ideas. So, the present study was aimed to assess staff nurses' perception of head nurses' support for creativity at Main Tanta University Hospital ${ }^{(39)}$.

\section{Levels of staff nurses' perception of head nurses' support}

Finding of the current study showed that the majority of staff nurses had high perception of head nurses' support as a total with high mean percent. This finding means that staff nurses believed in head nurses' support and they recognize the importance of it in promoting creativity.
Further, they saw head nurses' support as critical in enabling them to function more effectively and cope better with the pressures and constraints under which they work . This result is supported by Naserdin et al. ${ }^{(40)}$ and Woodhead et al. (2018) $^{(41)}$ who found that nurses had high level of support. Abo-Gad (2018) ${ }^{(42)}$ found that staff nurses perceived that management support as the highest mean percent at EL-Mogamaa EL-Tepee Hospital . Similarly, Masum et al. (2016) $^{(43)}$ found that the nurses reported high level of satisfaction with the leader support.

On contrary Zein (2019) ${ }^{(44)}$ showed that high percent of staff nurses had moderate perception level of support . Also, Abd El-Aziz et al. (2017) $)^{(45)}$ found that more than two fifth of staff nurses had moderate perception level regarding nursing supervisors' support at critical and noncritical care units. Chen et al. (2016) ${ }^{(46)}$ found that nurses perceived medium- to high-level support and the least source of social support male nurses perceived was from supervisors. Sodeify et al. (2013) ${ }^{(47)}$ found that the nurses perceived low level of the supervisors' support.

Additionally, Radwan (2019) $)^{(48)}$ found that nearly half of the staff reported that they don't have access to support. 
Elsherben (2018) ${ }^{(49)}$ indicated that nearly two thirds of Mansoura University Hospital's nurses expressed low job satisfaction due to lack of supervisors' support at work. Also, Xerri (2013) ${ }^{(10)}$ results indicated that nursing employees perceived low level of organizational support

The present study result displayed that the highest mean percentage of staff nurses was given to emotional support followed by informational support, appraisal support and instrumental support. This result means that emotional support is a critical need for staff nurses and they need to feel valued, cared for, respected and liked particularly in times of stress or when dealing with challenging or distressing issues related to clients and their treatment. When staff nurses feel valued and cared about by head nurses, this help them to be motivated, encouraged and stimulated in order to purposefully capture, disseminate, transfer and apply existing and newly generated knowledge . Result of Li et al. (2015) ${ }^{(50)}$ indicated that there is a lower level of emotional exhaustion with more informational, emotional, instrumental and appraisal support from supervisors.

Concerning levels of staff nurses' creativity.

The present study result displayed that the majority of staff nurses had high level of creativity as total. This result may be related to staff nurses had high perception level of head nurses' support for their creativity through providing emotional, appraisal, informational and instrumental support. Further staff nurses tend to engage in more rather than less creative behaviors because their head nurses exhibit certain behaviors including showing interest for new ideas, providing individualized coaching, clarifying expectations about work efforts and providing meaningful recognition.

The study result confirmed by Shehadeh $(2016)^{(51)}$ who showed that their respondents had high level of creative behavior. Also, Isfahani et al. (2015) ${ }^{(29)}$ displayed that nurses are creative and they are able to overcome many complex health care challenges at their workplace. Kasasbeh et al., (2014) ${ }^{(52)}$ showed that their respondents high perception of creativity. As well as,Ahmadian et al $\mathbf{( 2 0 1 2}^{(53)}$ found that more than fifty percent of nurses had desirable level of creativity.

The finding of the present study is inconsistent with the result of AbdElrhaman and Ghoneimy (2018) ${ }^{(54)}$ found that the majority of staff nurses had low level of creativity as total, Tabarestani et al. (2014) ${ }^{(31)}$ stated that nurses had moderate level of creativity in 
general , and Saleh et al. (2013) $)^{(55)}$ showed that more than three quarters of staff nurses were below average level of creativity .

The present study result revealed that high percent of staff nurses had high levels of ability analysis, risk taking, originality, sensitivity to problems, mental flexibility and intellectual fluency elements of staff nurses' creativity. This may be related to high percentage of staff nurses agree about all items of aforementioned elements of staff nurses' creativity. But AbdEIrhaman and Ghoneimy (2018) ${ }^{(54)}$ found that the majority of staff nurses had low level in all elements of creativity. Mohammed and Mustafa (2018)

found that almost sixty of head nurses had moderate level in mental flexibility, risk taking, sensitivity to problems, originality, ability analysis and intellectual fluency dimensions of creativity.

The present study result revealed that the highest mean percentage of staff nurses was given to the ability analysis, followed by originality, risk taking, sensitivity to problem, intellectual fluency, and mental flexibility. This may be related to staff nurses believed in the importance of quickly understanding of a situation and analyze it to solve problems by making decisions using the available information .
On contrary with Yossef and Rakha $\mathbf{( 2 0 1 7}^{(57)}$, found that nurses are sensitive to problems with a high level, followed by a high level of flexibility, and the analysis capability. Also, Tabaresani et al $\mathbf{( 2 0 1 4 )}^{(31)}$ stated that more than sixty of nurses had highest level of creativity related to solve problem in collaboration with others and in fluency dimension of creativity. Moreover, Daemi and Barforoosh (2014) $)^{(58)}$ in their study concluded that greatest amount of creativity is related to fluency; medium creativity is related the flexibility.

\section{Concerning correlation between staff} nurses' creativity and their perception of head nurses' support.

The present study result shows a statistically significant correlation was found between staff nurses' creativity and their perception of head nurses' support. This result may be related to that head nurses' support can enhance creativity by providing structure, resources and psychological conditions that help and motivate nurses to be involved in the creative process and exhibit creativity. Creativity of staff nurses requires time and effort from head nurses by procuring essential resources such as materials, funding, access to information and providing constructive feedback about their performance . 
This result is supported by the result of Ibrahim and Shahbudin (2016) $)^{(59)}$ who concluded that perceived managerial support is significantly related to creativity. When nurses perceive that managers supports them through training and coaching activities this in turns motivates them to be more creative at the workplace. The significant results indicate that when the staff nurses perceived there is support for creativity from their organization and managers, the positive perception increased with developmental experiences and exposure provided by the organization.

This result goes in the same direction with Shalley and Zhou, (2012) $)^{(60)}$ who showed that supervisor/ coworker's support for creativity may stimulate creative performance. It has been suggested that in order to be creative, staff nurses should feel safe and supported in their workplaces. Support from supervisors and coworkers may serve to moderate the effects of contextual conditions on creativity. Oldham (2011) ${ }^{(61)}$ explained that nurses who receive high levels of support will exhibit higher creativity in response to intermediate pressure than those who receive low levels of support.

Moreover, Madjar et al. (2012) ${ }^{(62)}$ demonstrated that non-work support also influences creativity at work for nurses with relatively low levels of creative personality. On contrary to, Zhou (2010) $^{(63)}$ who found no statistically significant relation between nurses' creativity and supervisors' developmental feedback, but demonstrated that feedback interacted with the presence of creative coworkers to affect creativity.

\section{Conclusion}

The majority of staff nurses had high perception of head nurses' instrumental, Informational, emotional, and appraisal support. Regarding to staff nurses' creativity, the majority of them had high levels of creativity and its elements of intellectual fluency, mental flexibility, sensitivity to problems, originality, risk taking, and ability analysis. Positive correlation was detected between staff nurses' perception of head nurses' support and their creativity.

\section{Recommendations}

Based on the results of the present study the following recommendation are suggested for:

\section{Health care organization}

1-Prime importance for follow up to reinforce head nurses' supportive role and keep the progress of nurses' creativity.

2-Prime importance the availability of adequate number of staff nurses to decrease workload on them and to have 
enough time to search for new information help them to solve problems creatively.

3-Encouraging good work environment in which teamwork is facilitated and nurses can incorporate self-confidence and autonomy to think more creatively.

4-Supporting work environment by enough resources, preparation and time that help in building relationships and stimulating staff nurses' creativity.

5-Integrating the usage of technology that influences staff nurses' performance as well as makes work more efficient and motivates staff nurses to be creative.

\section{Head nurses}

6-Setting up educational program for newly head nurses is important regarding support components and keep nurses' creativity.

7-Respond positively to nurses' creativity efforts by providing time, resources and adequate information.

8- Interpersonal relationships with staff nurses that can promote open exchange of ideas, culture, beliefs and feeling that promote nurses creativity.

9-Reassuring team attitude that encourage cooperation, empowerment, participative decision making and learning that promote nurses' creativity.

10-Empowering newly nursing staff by periodic feedback, training and opportunities to solve problems and find creative solutions.

11-Head nurses have to provide more opportunities for staff nurses to express their ideas and opinions, as well as setup an orientation programs for newly staff nurses about the importance of creativity and its role in developing heath care systems.

12-Interviewing with staff nurses' periodically, listen to their needs and specifies time for solving their problems as a way to improve the support level and in turns increase creativity level of staff nurses.

13-Building culture of self-learning and self-professional development.

\section{For further researches:}

a- Relations between head nurses' support and other factors in the work environment such as productivity, psychological wellbeing, absenteeism and turnover.

b-Study factors that affect creativity among nursing staff.

c- Administrative strategies for enhancing newly head nurses' supportive role to nursing staff.

\section{References}

1. Malik N, Dhar R. Authentic Leadership and its impact on extra role behavior of nurses: the mediating role of psychological capital and moderating role of autonomy. 
Personnel Review. 2017; 46 (2): $277-$

296. Available from: https://doi.org 10.1108 pr-05-2015-0140

2. İkiz F, Yörük C, Asici E, Tanrıkulu M, Ceylan İ, Öztürk B. Creativity, entrepreneurship and psychological counselıng. Journal of Western Anatolia of Educational Sciences. 2015; 6(1): 33-53.

3. Taha A, Sirková $M$, Ferencová $M$. The impact of organizational culture on creativity and innovation .Polish Journal of Management Studies. 2016; 14 (1): 7-17.

4. Çam MO, Turgut EÖ, Büyükbayram A. Resiliency and creativity in psychiatric and mental health nursing. Journal of Psychiatric Nursing. 2014; 5(3):160-3.

5. Şengün H. Innovation in healthcare delivery. Journal of Applied Psychology. 2016; 54(4): 194-8.

6. Brown H, Edelmann R. A study of expected and experienced stressors and support reported by students and qualified nurses. Journal of Advanced Nursing. 2010; 31 (4): 857-64.

7. Kalidass A, Bahron A. The relationship between perceived supervisor support, perceived organizational support, organizational commitment and employee turnover intention, International Journal of
Business Administration. 2014; 4 (2): 83-88. Doi:10.25659/2530-5283/1431

8. Nodu N. Instrumental support for professional nurses caring for patients. Africa Journal of Nursing and Midwifery. 2018; 19(3):13. Doi:10.25159/2520-5293/1631

9. Newman A, Thanacoody R, Hui W. The effects of perceived organizational support, perceived supervisor support and intra organizational network resources on turnover intentions: A study of Chinese employees in multinational enterprises. Personnel Review. 2011; 49(9): 2-63.

10. Xerri M. Workplace relationships and innovation behavior of nursing employees: A social exchange perspective . Asia Pacific Journal of Human Resources. 2012; 51 (1): 103 -123.

\section{Shacklock K, Brunetto Y, Teo S,} Farr-Wharton R. The role of support antecedents in nurses' intentions to quit: The Case of Australia, Journal of Advanced Nursing. 2014; 63(4): 899833.

12. Dorner N. Innovative work behavior the role of employee expectations and effects on job performance. Published Doctoral Thesis. Gallen University. 2012: 98 - 103.Available at http: // 
www.researcgate. Net/publication /286953807-

13. Renjith V, Anice R. Leadership in nursing. International Journal of Research and Management Studies. (2012); 2(2):112 -118.

14. Solbakken R, Bergdahl E, Rudolfsson G, Bondas T. Caring in nursing leadership a Meta ethnography from the nurse leaders' perspective. Nurs. Admin. Q. 2018; 42 (4) : 1- 19.

15. Çam MO, Turgut EÖ. Creativity in psychiatric and mental health nursing. Journal of Psychiatric Nursing. 2015; $6(1): 1-3$.

16. Ebraheem S, Ahmed G, Mahfouz H. Enhancing creativity and change of nursing management staff and its influencing on their performance. Unpublished Decrate Thesis. Faculty of Nursing. Benha University. 2017: 91-100

17. Yilmaz E. The analysis of organizational creativity in schools regarding principals ethical leadership characteristics. Proc. Soc. Behav. Sci. 2010; 2(1): 3949-53.

18. Oke A, Munshi N, Walumbwa F. The influence of leadership on innovation processes and activities. Organizational Dynamics. 2011; 38 (1): 64-72.
19. Gumusluoglu L, Ilsev A. Transformational leadership, creativity, and organizational innovation. Journal of Business Research. 2010; 62(1): 461-473.

20. Fasnachat P. Creativity: A refinement of the concept for nursing practice. Journal of Nursing Studies. 2013; 41(2): $\quad$ 195-202. Doi $: 10.1016 / j . n e d t .2013 .09 .005$

21. Grant M, Berry J. The necessity of others is the mother of invention: intrinsic and pro-social motivations, perspective taking, and creativity. Academy of Management Journal. 2011:73-96.

22. Joyti J, Dev M. Transformational leadership and nurses' creativity. Journal of Asia Business Studies. 2015; 9(1): 78-98. Doi:10.1108.JABS03-2014-0022

\section{Fathizade A, Pakniyat A, Shahba}

M. Assessment of creativity and innovation in public administration education, agriculture and health sir Jan city and provide a model for increased creativity and innovation in organizations. Management Journal. 2011; 12(8): 79-94.

24. Corcoran K, Fischer J. Social research methods: A complete guide. $5^{\text {th }}$ Ed. New York: Oxford University 
Press. 2013. $815-9$.

25. El-Shaer A. Staff nurses perception of job empowerment and organizational commitment at Mansoura University Hospital. Unpublished Master Thesis. Cairo University. Faculty of Nursing. 2012: 13 .

\section{Papadatou D, Papazoglou I,} PetrakiD, Bellali T. Mutual Support among Nurses who Provide Care to Dying Children. Illness, Crisis and Loss. 1999; 1(7): 37-48.

27. Kelly N, Antonio A. Teacher peer support in social network sites. Teaching and Teacher Education. 2016; 56(1): 138-149. Available from:https://doi.org/10.1016/j.tate.201 6.02 .007

28. Andersson C, Palm T. The impact of formative assessment on student achievement: A study of the effects of changes to classroom practice after a comprehensive professional development programme. Learning and Instruction. 2017; 49(1): 92-102. Availablefrom:https://doi.org/10.1016/ j.learninstruc.2016.12.006

29. Isfahani S, Hosseini M, Khoshknab M, Peyrovi H, Reza K .Nurses' creativity: Advantage or disadvantage. Iran Red Crescent Med Journal. 2015; 17(2):1-6.
30. Burleson B. The experience and effects of emotional support: what the study of cultural and gender differences can tell us about close relationships, emotional and interpersonal communication. Personal Relationships. 2013; 10(1): 1-23.

31. Tabarestania M, Shooridehb F, Jahanic M, Poord M, Majde $H$. Creativity and effective factors on hospital nurses creativity. Scientific Journal of Pure and Applied Sciences. 2014; 3(8): 741-47.

32. Kalf H. The Relationship between transformational leadership and the creative management among academics heads departments at the Islamic University in Gaza. Published Master Thesis. Faculty of Commerce. Islamic University. 2010:1160 -1164. Available at: P http: // www.researcgate. Net/publication /283953807- The relationship between transformational leadership and the creative management among academics heads departments in Gaza.

33. Gumusluoglu L, Ilsev A. Transformational Leadership, Creativity, and Organizational Innovation. Journal of Business Research. 2014;33(9): 461-73. 
34. Salehe J, Dehghan N. The relationship between psychological empowerment of employees' creativity by using multiple regression (Case Study: Tehran Technical Services Co). Quantitat. Stud. Manag. 2010; 1(2): 31-48.

35. Zare H. Examine the relationship between organizational climate, job stress and employees' creativity (male and female) in education office of West Azerbaijan Province. Behav. Sci. Res. 2010; 5(2): 114-124.

36. Zhang X, Bartol K. Linking empowering leadership and employee creativity: The influence of psychological empowerment, intrinsic motivation, and creative process engagement. Academy of Management Journal. 2010; 53(1):107-128.

37. Juruena A. The impact of head nurses perceived support relationship on staff nurses' performance outcomes. International Journal Nursing and Hospital Care. 2018; 1(1):01.

38. Chan Z. A systematic review of creative thinking/creativity in nursing education. Nurse Educ. Today. 2013; 33(11): 1382-1387. Available from:http://dx.doi.org/10.1016/j

39. Bruise W, Zahiyya D. Impact of organizational creativity on the job performance in the corporation. Fourth scientific symposium research: creativity in the business world. Research and Development Center on Human Resources - Rammah Jordan. 2016 ; 3(7):81 - 96.

40. Naserdin A, Robaee N, Ashktorab T. Perceived organizational support and moral distress among nurses. BMC Nurs. .2018; 10(17): 22-28.

\section{Woodhead A, Lynn N, Eldestein B.} Stress, social support and burnout among long term care nursing staff. 2018. 7(33): 149-157.

42. Abo Gad R. The influence of nurse manager leadership practices and organizational characteristics on staff nurses innovation: A comparative study. Journal of Nursing and Health Sciences. 2018; 7 (5): 73-86.

43. Masum A , Azad M , Hoquek K, Seebeh L, Wanke P, Arslan Ö. Job satisfaction and intention to quit: An Empirical Analysis of Nurses in Turkey. Peer Journal. 2016; 4(1): 18 - 96.

44. Zein A. Nurses job demands, controls and social support and its effect on their job performance. Unpublished Master Thesis. Faculty of Nursing. Benha University. 2019.

\section{Abdel Aziz A, Hassan R, KamelF.} Perceived nursing supervisor support and is relation to turnover intention 
among staff nurses .Egyptian Journal of health care. $2017 ; 8(2): 172-182$.

46. Chen X, Ran G, Ma Y. Adult children's support and self-esteem as mediators in the relationship between attachment and subjective well-being in older adults. Personality and Individual Differences. 2016; 97(1): 229-233.

\section{Sodeify R, Vanaki Z, Moammadi E.}

Nurses experiences of perceived support and their contributing factors: A qualitative nursing and midwifery research. 2013; 18 (3):191-197.

48. Radwan G. Work empowerment and patient safety culture among nursing staff. Unpublished Master Thesis. Faculty of Nursing. Tanta University. Egypt. 2019. 10 - 90.

49. El-Sherben E. Job satisfaction among nurses working in Mansoura university hospital: effect of socio demographics and work characteristics. Egyptian Journal of occupational medicine. 2018; 42(2): 227-240.

50. Li S, Chang W, Li C. The effectiveness of modified restraint glove in critical ill patients". Journal of Health and Architecture. 2015; 2(1): $65-73$.

51. Shehadeh H. Impact of the organizational culture on creative behavior: A field study on a sample of Commercial Banks Operating in Jordan. European Scientific Journal. 2016; 12(25): 214-235. Available from:

https://eujournal.org/index.php/esj/arti cle/download/8014/7710

52. Kasasbeh E, Harada Y, Osman A, Noor I. The impact of the transformational leadership in the administrative creativity: An Applicative Study. International Journal of Academic Research in Business and Social Sciences. 2014; 4(5): 382-394.Available from:http://dx.doi.org/10.6007/IJARB SS/v4-i5/870.

\section{Ahmadian Z, AshghaleFarahane $M$}

, Bastane $\mathbf{F}$, Haghane $\mathbf{H}$. Organizational culture of hospitals nurses Tehran University of Medical Sciences. Journal of Nursing and Midwifery. Tehran Univ. Med. Sci. 2012; 3(1): 76-89.

\section{Abd-EIrhaman E, Ghoneimy A.} Creativity in Work: an educational program for improving nurses' productivity. International Journal of Innovative Research \& Development. 2018; 7

(9):71-83

Doi:10.24940/ijird/2018/v7/i9/SEP180 14 
55. Saleh N, Al Sayed N, Ghallab S, Abd Alaa S. Nurse leaders behavior and its effect on nurses creativity at Main Assuit University hospital. Journal of American Sciences. 2013; 9 (12): 207-209.

\section{Mohammed A, Mostafa A.} Relationship between first line nurse managers transformational leadership practices and nurses' perception of structural empowerment. Unpublished Master Thesis. Faculty of Nursing. Alexandria University. 2018.

57. Yossef S, Rakha H. Efficiency of personal and administrative skills for managerial leadership on administrative creativity at Najran University. Journal of Education and Practice. $\quad 2017 ; \quad 8(6):$ 113-122. Available from: www.iiste.org.

58. Daemi H, BarforoshF. Creative test standardization. New Cognit. Sci. (2014); 4(3): 1-8.

59. Ibrahim H, Abdul-Kareem M, Shahbudin A. Organizational support and creativity: The role of developmental experiences as a moderator. Procedia. Economics and Finance. 2016; 35(1): 509 -514.

60. Shalley C, Zhou J. The effects of personal and contextual characteristics on creativity: Where should we go from here? Journal of Management. 2012; 30(1): 933-958.

61. Oldham G. Employee creativity: Personal and contextual factors at work. Academy of Management Journal.2011; 39 (3): 607-34.

62. Madjar N, Oldham G, Pratt M. There's noplace like home? The contributions of work and non-work creativity support to employees' creative performance. Academy of Management. 2012; 45(4): 757-767.

Zhou J. When the presence of creative co-workers is related to creativity: role of supervisor close monitoring, developmental feedback, and creative personality. Journal of Applied Psychology.2010; 88 (3): 413- 